\title{
Physical simulation and dilatometric study of double-step heat treatment of medium-Mn steel
}

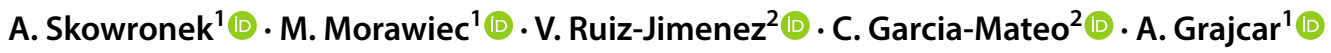

Received: 21 August 2020 / Revised: 2 October 2020 / Accepted: 16 October 2020

(c) The Author(s) 2020

\begin{abstract}
The work addresses physical simulation and dilatometric study of one-step and double-step heat treatments of medium-Mn steel designed for automotive sheets. The conventional one-step isothermal bainitic transformation was applied as the reference heat treatment. The newly implemented heat treatment consisted of isothermal holding in a bainitic region followed by additional holding of the material at reduced temperature also in the bainitic range. This step was added to refine the microstructure, which led to the stabilization of the retained austenite. Calculations of equilibrium state and non-equilibrium cooling and simulations of the developed thermal cycles were performed using the thermodynamic JMatPro software. The physical simulations of the heat treatment were performed in the dilatometer. The obtained samples were subjected to microscopic observations using light and SEM microscopy. One- and two-step heat treatments allowed to obtain bainitic structures with high contents of retained austenite. Lowering the temperature of one-step isothermal holding resulted in the bainite refinement and adjacent retained austenite. The increased $\mathrm{Mn}$ content in steel increased its susceptibility to form coalesced bainite resulting in the partial formation of thicker plates despite a decrease in a process temperature.
\end{abstract}

Keywords Dilatometric study $\cdot$ Medium-Mn sheet steel $\cdot$ Complex microstructure $\cdot$ Bainitic transformation $\cdot$ Retained austenite

\section{Introduction}

Medium-manganese sheet steels containing 3-12 wt $\%$ Mn and belonging to the third generation of AHSS (Advanced High Strength Steels) are currently very popular among researchers and industry due to the combination of high strength properties and relatively good plasticity. There are several variants of heat treatment for these steels: intercritical annealing after cold rolling [1] or hot rolling [2], and isothermal holding in a bainitic region [3]. The goal of each is to obtain a large fraction of retained austenite in the structure characterized by optimal thermal and mechanical stabilities. To do this, it is necessary to enrich the austenite with stabilizing elements—carbon and manganese-thanks

A. Skowronek

adam.skowronek@polsl.pl

1 Department of Engineering Materials and Biomaterials, Silesian University of Technology, Konarkiego 18a St., 44-100 Gliwice, Poland

2 National Center for Metallurgical Research, Av. de Gregorio del Amo 8, 28040 Madrid, Spain to which the $M_{s \gamma}$ (martensite start) temperature is reduced and thus there is no martensitic transformation during the steel cooling to room temperature. Retained austenite as a metastable phase [4] increases the work-hardening rate and plasticity at the same time due to the TRIP (Transformation Induced Plasticity) effect [5]. This effect is based on the tendency of the metastable austenite to undergo the straininduced martensitic transformation.

Depending on the strength requirements of medium-Mn steels, different complex structures can be obtained using appropriate heat treatments. In general, the so-called intercritical annealing [6] can be applied for cold-rolled sheets [7], whereas thermomechanical processing is used for hotrolled sheets [8]. The intercritical annealing is carried out in the $\alpha+\gamma$ area following the cold rolling of steel sheets [9]. During annealing at $650-720^{\circ} \mathrm{C}$ (depending on a chemical composition) the $\gamma$ phase is formed upon heating as a result of the austenite reverse transformation (ART) from roomtemperature martensite. The austenite is enriched in carbon from the ferrite being the second microstructural constituent. For sufficiently long times, the additional manganese enrichment of the $\gamma$ phase can take place [10]. The chemically 
stabilized austenite maintains its thermal stability to room temperature during successive one-step cooling form the intercritical temperature range [11].

The treatment applied for the hot-rolled products utilizes the isothermal bainitic transformation to stabilize retained austenite. The enrichment carbon of the austenite is due to its redistribution right after the formation of new bainitic ferrite plate [12]. However, austenite stability does not depend only on its chemical composition (chemical stabilization) but also on a grain size and a morphology of structural constituents (mechanical stabilization). Along with the reduction of austenite grain size, its stability increases significantly [13].

Previous studies conducted on bainitic steels showed that it is possible to significantly improve their strength-plasticity balance due to isothermal bainitic transformation at low temperatures [14]. The mentioned heat treatments allow for the production of fine-grained bainitic plates [15] and carbonenriched retained austenite [16]. It has been proved that as the size of the bainitic plate decreases the retained austenite distributed between them is also subjected to some refinement [17]. Hence, the further increase in strength properties of all microstructural constituents can be expected [18]. The lowering the bainitic transformation temperature introduces also compressive stresses into the retained austenite [19]. This phenomenon increases the stability of retained austenite [20].

The factor conditioning the performance of isothermal bainitic transformation at reduced temperature is the content of $\mathrm{C}$ in steel. It is a critical element having a direct impact on bainite and martensite temperatures, $\mathrm{B}_{\mathrm{s}}$ and $\mathrm{M}_{\mathrm{s}}$ respectively. Currently, there is a tendency to limit the carbon content due to its negative impact on the weldability of steel sheets increasing the risk of material cracking in the heat-affected zone [21]. Usually, the $\mathrm{M}_{\mathrm{s}}$ temperature is not low enough to obtain an ultrafine-grained structure in low-C steels. Thus, the partial ferrite formation during intercritical annealing results in a further austenite enrichment in carbon and reduces its $M_{s \gamma}$ temperature sufficiently to be able to perform the next stage of isothermal bainitic heat treatment at a lower temperature [22]. This method has already been used in ferrite-based TRIP steels [23]. Another interesting method has been proposed by Long et al. [24]. This method consists in a double-step isothermal treatment in the bainitic area, $\mathrm{T}<\mathrm{B}_{\mathrm{s}}$. During the first step, there is a partial bainitic transformation, which results in carbon enrichment of the remaining part of the austenite from the bainitic ferrite plates, resulting in a reduction of the $\mathrm{M}_{\mathrm{s} \gamma}$ temperature. Thanks to this, it is possible to decrease even more the holding temperature in the second transformation step without starting the martensitic transformation [25]. The final result is the formation of a second finer fraction of bainitic ferrite plates with the consequent refinement of the remaining austenite, which is further enriched in carbon. The final microstructure consists of bainitic ferrite with two different plate sizes and layers of strongly enriched in C retained austenite [26].

Soliman et al. [27] proved that the use of two-stage isothermal treatment in the bainitic area leads to a significant refinement of bainitic plates and thus increases the strength properties of low-C multiphase steels containing $0.26 \% \mathrm{C}$. Wang et al. [28] and Mousalou et al. [29] by performing the multi-step isothermal treatment reported a decrease in the thickness of bainitic plates along with a decrease in the test temperature, and thus an improvement in plastic properties of the material. The two-step holding was also performed for TRIP steels indicating the higher susceptibility of medium-C than low-C steels to this type of treatment [30].

Other studies on TRIP steels also indicated the impact of the double-step treatment on a change in the morphology of retained austenite. Sugimoto et al. [31] reported that martensitic transformation of blocky grains of retained austenite during hole-punching of steel sheets resulted in their worse stretch flangeability. The change of the blocky morphology of austenite to the film-like resulted in improving its stability and formability of punched sheet edges [32]. Moreover, the hard bainitic ferrite plates adjacent to the austenite films create the hydrostatic pressure counteracting the martensitic transformation. This results in the decrease of $\mathrm{M}_{\mathrm{s} \gamma}$ temperature and stabilizes further the retained austenite [33]. A lack of the blocky grains and resulting good stretch-flangeability are present for isothermal bainitic holdings below $400{ }^{\circ} \mathrm{C}$ [34].

Previous studies on double-step heat treatment have usually concerned conventional TRIP-aided bainitic steels. Due to the wide interest and development of medium-manganese steels and the constant requirement to improve the formability of multiphase steel sheets, the aim of the current study was to design the one-step and two-step bainitic isothermal treatments in order to determine the impact of the treatments on the phase transformation behavior and microstructural features of novel lean medium-Mn steel with an increased aluminum content.

\section{Experimental procedure}

The studied medium-Mn steel has the nominal composition of 3.3 wt.\% Mn, 0.17 wt.\% C, 1.6 wt.\% Al, 0.23 wt.\% Mo and 0.22 wt.\% Si. The cast material with dimensions of $\varnothing 124 \mathrm{~mm} \times 200 \mathrm{~mm}$ was forged in the temperature range of $1200-900{ }^{\circ} \mathrm{C}$ to the final width $160 \mathrm{~mm}$ and a thickness of $22 \mathrm{~mm}$ as described in our previous study [35]. Then, dilatometric samples with dimensions $\varnothing 4 \mathrm{~mm} \times 10 \mathrm{~mm}$ were cut out from the wrought material according to the recommendations of the test equipment manufacturer. Thermodynamic calculations using the JMatPro software [36] with the implemented database ver. 11.2 General Steels Module 
have allowed to design the intended heat treatment cycles. For this purpose, calculations under equilibrium and nonequilibrium conditions were performed. A simulation of the thermal cycles was also performed to analyze phase transformations and amounts of the phases formed in the steel. The purpose of this procedure was to compare computational and experimental results.

The steel samples were heat treated in one- and doublestep cycles (Fig. 1), with both beginning with the sample austenitization at $1100{ }^{\circ} \mathrm{C}$ for $300 \mathrm{~s}$ followed by cooling the material to the isothermal holding temperature. In the case of
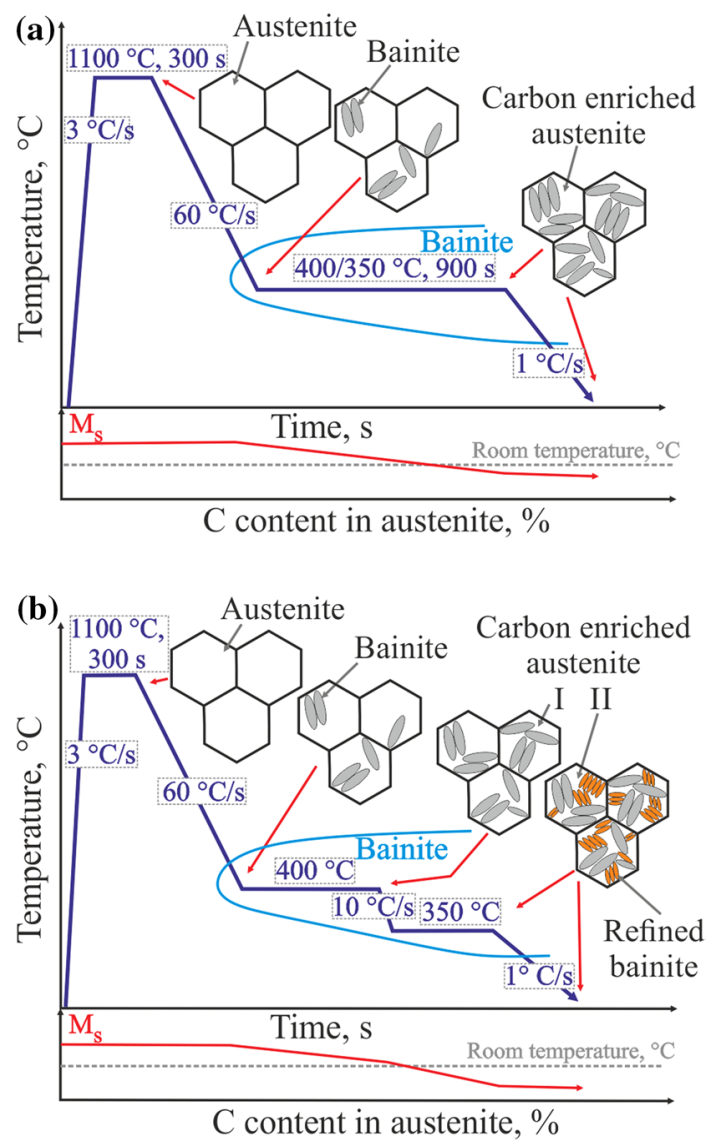

Fig. 1 Schematic diagrams of heat treatments performed during the tests; a One-step heat treatment; b Double-step heat treatment one-step heat treatment, the isothermal hold was performed for $900 \mathrm{~s}$ in two temperature variants: 400 and $350{ }^{\circ} \mathrm{C}$, followed by cooling to room temperature. The double-step heat treatment consisted of holding the material at $400{ }^{\circ} \mathrm{C}$ followed by a temperature reduction to $350{ }^{\circ} \mathrm{C}$. In this case, two time variants were used (Table 1) corresponding to the mentioned temperatures: $240 \mathrm{~s} / 660 \mathrm{~s}$ and $120 \mathrm{~s} / 780 \mathrm{~s}$. The total time of the isothermal treatment in all variants was always equal to $900 \mathrm{~s}$. The temperatures and times have been selected on the basis of thermodynamic calculations.

The designed heat treatment cycles were experimentally simulated in a BAHR high-resolution DIL805A/D dilatometer. The investigation and analysis of dilatograms and determination of critical temperatures were made according to ASTM A1033-04 [37]. The heating of samples was performed by an induction system and the temperature was controlled by a K-type thermocouple welded to the center of the specimen. The tests were performed in vacuum; helium cooling was applied. The microstructures were subjected to light microscopy (LM) using the Zeiss AxioObserver. For more accurate analysis of morphological details, the scanning electron microscopy (SEM) was performed using the Zeiss SUPRA 35, which allows observations at much higher magnifications and resolutions. The samples for the microscopic examination were cut in the center, perpendicular to their length, mechanically ground with $\mathrm{SiC}$ paper up to 2000 grid, mechanical polished and etched in $2 \%$ Nital according to standard metallographic procedures. The material hardness was measured by the Vickers method using the Microhardness Tester FB-700. During the test, a $100 \mathrm{~N}$ load was applied. Three measurements were performed for each sample, from which the mean value and standard deviation were calculated.

\section{Results}

\subsection{Theoretical calculations}

To estimate the optimal heat treatment parameters, thermodynamic calculations by means of JMatPro software were used. Figure 2 shows the phase evolution under

Table 1 Temperature-time characteristics of the heat treatment cycles applied

\begin{tabular}{|c|c|c|c|c|c|c|}
\hline \multirow[t]{2}{*}{ Variant } & \multirow[t]{2}{*}{ Heat treatment } & \multirow{2}{*}{$\begin{array}{l}\text { Austenitization } \\
\text { Temperature, }{ }^{\circ} \mathrm{C}\end{array}$} & \multicolumn{2}{|c|}{ 1st Isothermal step } & \multicolumn{2}{|c|}{ 2nd Isothermal step } \\
\hline & & & $\begin{array}{l}\text { Temperature, } \\
{ }^{\circ} \mathrm{C}\end{array}$ & Time, $\mathrm{s}$ & Temperature, ${ }^{\circ} \mathrm{C}$ & Time, $\mathrm{s}$ \\
\hline $400{ }^{\circ} \mathrm{C}-900 \mathrm{~s}$ & One-step & 1100 & 400 & 900 & Not applicable & \\
\hline $350{ }^{\circ} \mathrm{C}-900 \mathrm{~s}$ & & & 350 & 900 & & \\
\hline $400{ }^{\circ} \mathrm{C}-240 \mathrm{~s} / 350^{\circ} \mathrm{C}-660 \mathrm{~s}$ & Double-step & 1100 & 400 & 240 & 350 & 660 \\
\hline $400{ }^{\circ} \mathrm{C}-120 \mathrm{~s} / 350{ }^{\circ} \mathrm{C}-780 \mathrm{~s}$ & & & 400 & 120 & 350 & 780 \\
\hline
\end{tabular}



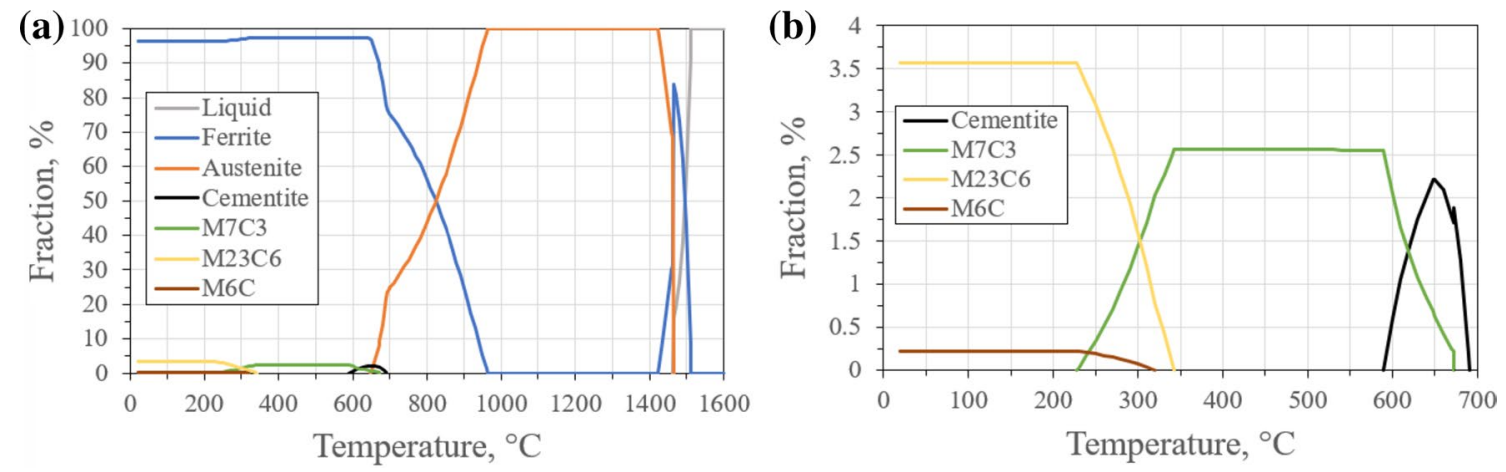

Fig. 2 Phase evolution diagrams of the steel under equilibrium conditions: a Full temperature range; $\mathbf{b}$ a magnified part of the diagram

equilibrium conditions. The calculations indicate that the microstructure is $100 \% \gamma$ in the temperature range from 1430 to $950{ }^{\circ} \mathrm{C}$. Below this temperature, ferritic transformation begins, which reaches its maximum at a temperature of $630{ }^{\circ} \mathrm{C}$. Therefore, the $\mathrm{A}_{\mathrm{c} 3}$ temperature is $\sim 970{ }^{\circ} \mathrm{C}$ and $\mathrm{A}_{\mathrm{c} 1} \sim 630{ }^{\circ} \mathrm{C}$. Moreover, one can see that below $700{ }^{\circ} \mathrm{C}$, the formation of carbides takes place, which can affect the binding of carbon, needed to stabilize the austenite. The enlargement of a fragment of the graph in Fig. 2 shows that $\mathrm{M}_{7} \mathrm{C}_{3}$ formation begins at a temperature of ca. $680{ }^{\circ} \mathrm{C}$. But at $220{ }^{\circ} \mathrm{C}$, formation of $\mathrm{M}_{23} \mathrm{C}_{6}$ and a small amount of $\mathrm{M}_{6} \mathrm{C}$ phase seems more plausible. The thermodynamic analysis indicates that in the studied steel, the use of an annealing temperature $1100{ }^{\circ} \mathrm{C}$ is sufficient to obtain the intended full austenitization. This value is also consistent with the technological processes used in the industry.

Figure 3a, b shows CCT (Continuous Cooling Transformation) and TTT (Temperature Time Transformation) plots calculated for non-equilibrium conditions, respectively. The $A_{c 1}$ temperature $\left(692{ }^{\circ} \mathrm{C}\right)$ shown at Fig. 3a is clearly higher than the one obtained under the equilibrium calculations: $630{ }^{\circ} \mathrm{C}$. The reason for this is the diffusion that cannot keep up at high heating rates [38]. The calculated $\mathrm{M}_{\mathrm{s}}$ temperature is ca. $371{ }^{\circ} \mathrm{C}$. According to the CCT graph, the cooling rate of $60{ }^{\circ} \mathrm{C} / \mathrm{s}$ is enough to ensure that no transformation occurs during cooling to $400{ }^{\circ} \mathrm{C}$. The TTT diagram shows that bainitic transformation should begin almost immediately after reaching $400{ }^{\circ} \mathrm{C}$ and end after about $300 \mathrm{~s}$ (Fig. 3b).

In case of $350{ }^{\circ} \mathrm{C}$, temperature, some potential martensite formation is predicted as it is below the $\mathrm{M}_{\mathrm{s}}$ temperature. However, the start of isothermal holding step will stop this process allowing the bainitic transformation to take place. The presented calculations were used to develop the applied heat treatment cycles.
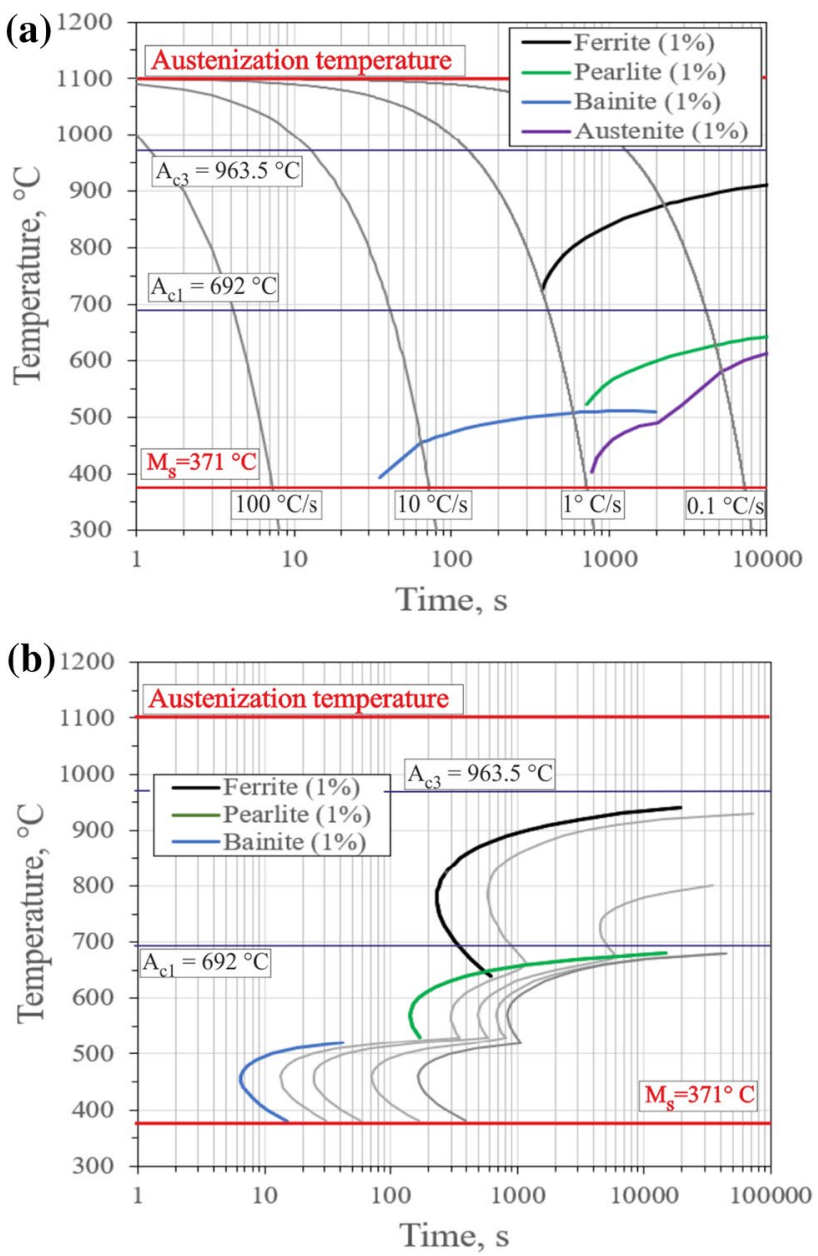

Fig. 3 Non-equilibrium diagrams for steel austenitized at $1100{ }^{\circ} \mathrm{C}$ : a CCT diagram; b TTT diagram

\subsection{Dilatometric results of one-step isothermal holding}

The first heat treatment was bainitic isothermal holding implemented in two temperature variants $\left(400{ }^{\circ} \mathrm{C}-900 \mathrm{~s}\right.$ and 
$350{ }^{\circ} \mathrm{C}-900$ s). Dilatometric results (Fig. 4a) indicate that for the investigated steel the $\mathrm{A}_{\mathrm{c} 1}$ and $\mathrm{A}_{\mathrm{c} 3}$ temperatures are $740{ }^{\circ} \mathrm{C}$ and $1020{ }^{\circ} \mathrm{C}$, respectively. The repeatability of measurements is very good as indicated by almost perfectly overlapping dilatometric curves. During cooling the material to the isothermal temperature, at $60^{\circ} \mathrm{C} / \mathrm{s}$ (Fig. $4 \mathrm{~b}$ ), no transformation occurs at $400{ }^{\circ} \mathrm{C}$, whereas at $350{ }^{\circ} \mathrm{C}$, as expected, a clear increase in the relative change in length (RCL) of about $0.2 \%$ indicates that austenite has crossed the $\mathrm{M}_{\mathrm{s}}$ temperature. The relative change in length (RCL) during the isothermal step in Fig. $4 \mathrm{c}$ indicates that in both cases bainitic transformation occurs. The sample processed at $350{ }^{\circ} \mathrm{C}$ shows very step initiation of the bainitic transformation caused by the presence of the prior-formed martensite [39]. At the higher temperature, the RCL of the sample during this transformation, lasting about $350 \mathrm{~s}$, increased up to $0.55 \%$, which is almost two times higher than that measured at $350{ }^{\circ} \mathrm{C}$ : $0.27 \%$ at completion of transformation after $290 \mathrm{~s}$. This is consistent with the fact that when earlier partial martensitic transformation has occurred, it decreases the amount of austenite available for bainitic transformation. The last stage (Fig. 4d), showing cooling of the generated microstructures to room temperature, did not record any transformation. This indicates that the remaining austenite was sufficiently C-enriched to remain stable at room temperature showing its high chemical stability.
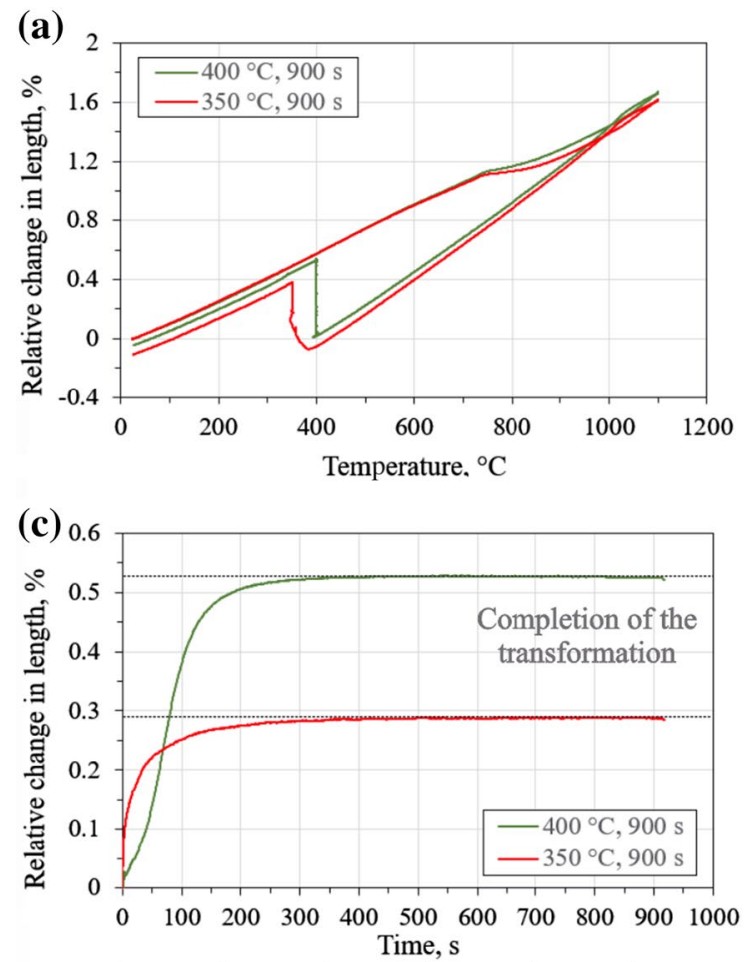

In agreement with the presented dilatometric results, light microscopic images (Fig. 5a, c) of both samples confirmed the presence of bainitic ferrite and retained austenite in the microstructures. For the sample treated at $400{ }^{\circ} \mathrm{C}$, the microstructure is composed of fine laths of bainite and interlath retained austenite (Fig. 5b). In case of the sample held at $350{ }^{\circ} \mathrm{C}$, the structure contains also a small fraction of tempered martensite and coalesced bainite. The formation of martensite was indicated by a dilatometric curve depicting cooling to the holding temperature (Fig. 4b). Interestingly, many of the bainitic ferrite plates are thicker (Fig. 5c) compared to the ones at $400{ }^{\circ} \mathrm{C}$. This is a result of coalescence of the individual bainite plates and the fragmentation of the austenite laths [40], which is typical in medium-Mn steels processed below ca. $400{ }^{\circ} \mathrm{C}$ [2]. The coalescence process is visible in Fig. 5d, where a mixture of decomposed M-A constituents and carbides are located inside thick bainite laths.

\subsection{Dilatometric results of double-step isothermal holding}

The purpose of the second heat treatment method (Fig. 1b) was to refine the bainite and residual austenite grains, and thus increase the mechanical and chemical stabilization of the latter. The times of the first step were selected assuming
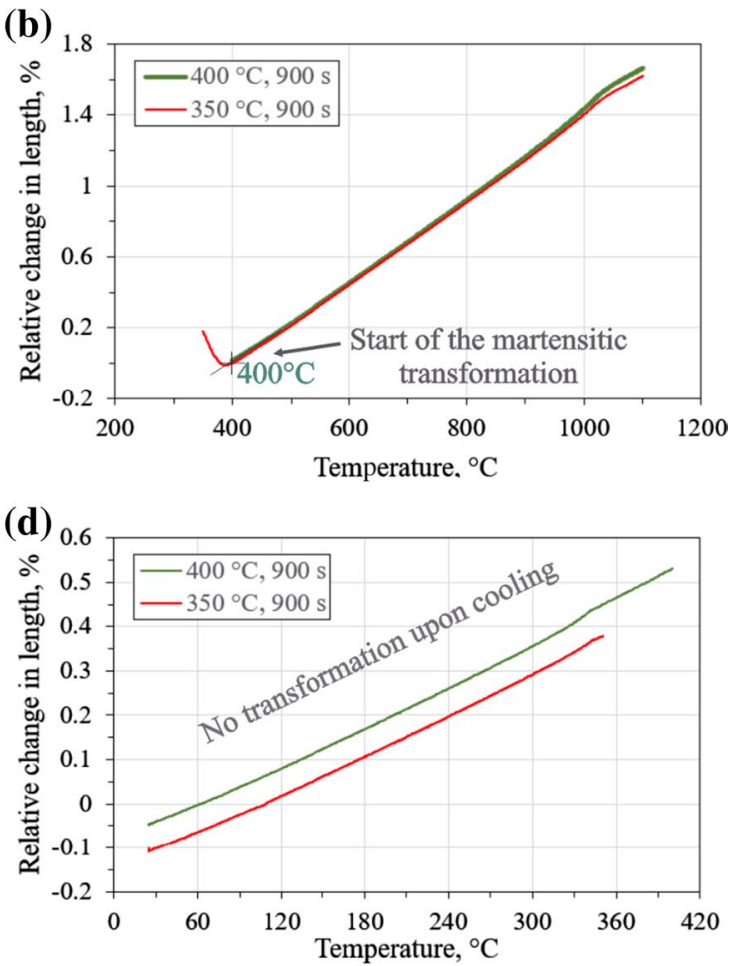

Fig. 4 Dilatometric curves of steel registered during the one-step heat treatment (a) heating and cooling throughout the entire heat treatment cycle; $\mathbf{b}$ cooling to isothermal holding temperature; $\mathbf{c}$ isothermal step; $\mathbf{d}$ cooling to room temperature 
Fig. 5 Microstructures of steel after one-step isothermal heat treatment: a $400{ }^{\circ} \mathrm{C}(\mathrm{LM})$, b $400{ }^{\circ} \mathrm{C}(\mathrm{SEM}), \mathbf{c} 350^{\circ} \mathrm{C}(\mathrm{LM})$ d $350{ }^{\circ} \mathrm{C}(\mathrm{SEM}) ; \gamma_{r}$ retained austenite, $\alpha_{b}$ bainite, $\alpha_{c b}$ coalesced bainite
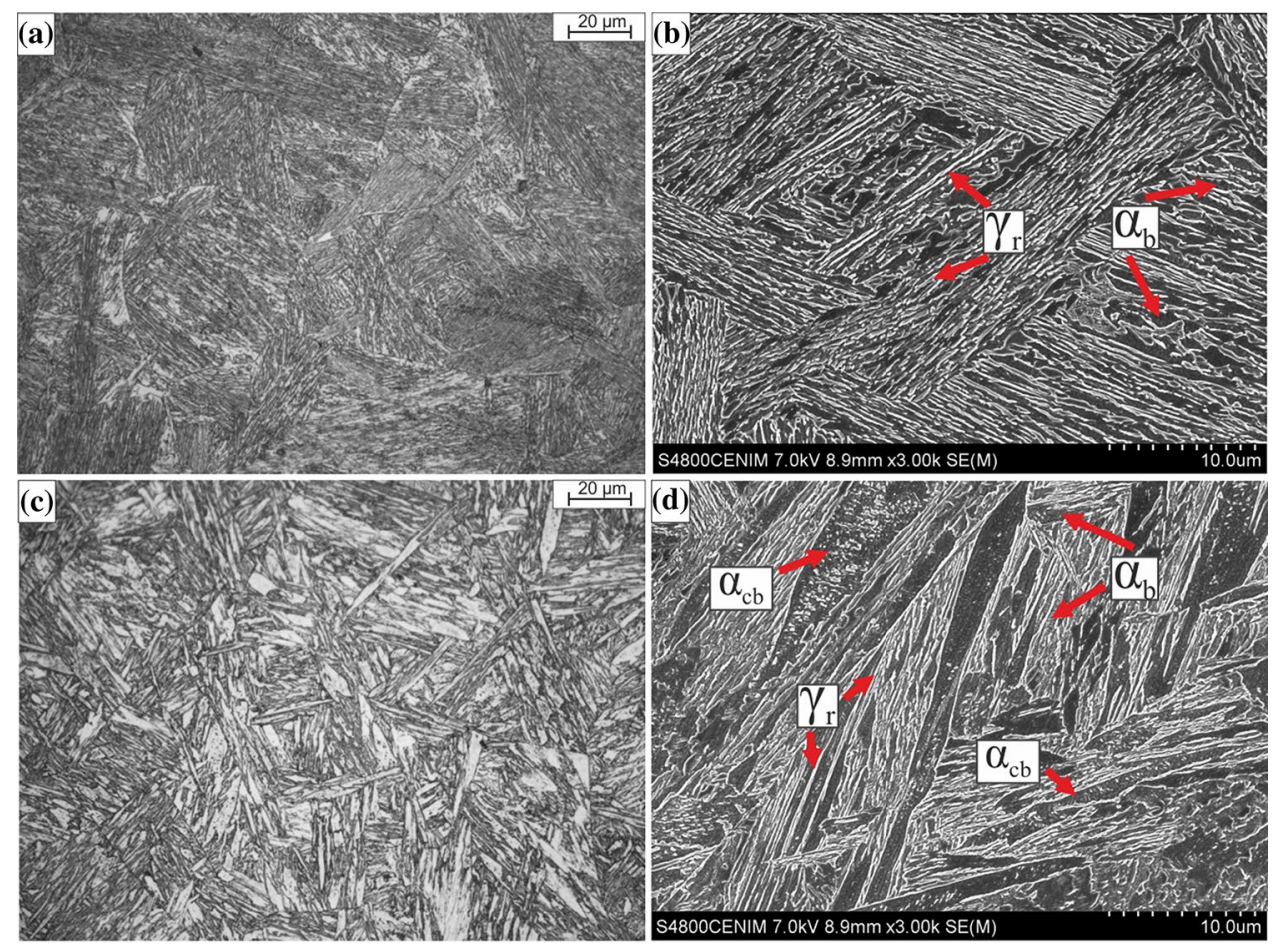

a partial bainitic transformation. From Fig. 6c, it is clear that $240 \mathrm{~s}$ (variant.

$400{ }^{\circ} \mathrm{C}-240 \mathrm{~s} / 350{ }^{\circ} \mathrm{C}-660 \mathrm{~s}$ ) or $120 \mathrm{~s}$ (variant $\left.400{ }^{\circ} \mathrm{C}-120 \mathrm{~s} / 350{ }^{\circ} \mathrm{C}-780 \mathrm{~s}\right)$ are enough to complete the transformation in $80-90 \%$ and $70-80 \%$, for the $240 \mathrm{~s}$ and $120 \mathrm{~s}$ holdings at $400{ }^{\circ} \mathrm{C}$, respectively. It should allow for further bainite formation at a lower temperature after the initial stabilization of austenite.

The $400{ }^{\circ} \mathrm{C}-240 \mathrm{~s} / 350{ }^{\circ} \mathrm{C}-660 \mathrm{~s}$ sample does not show any transformation during cooling (Fig. 6b), whereas the dilatometric curve of the $400{ }^{\circ} \mathrm{C}-120 \mathrm{~s} / 350{ }^{\circ} \mathrm{C}-780 \mathrm{~s}$ sample indicates the start of the phase transformation during cooling at $452{ }^{\circ} \mathrm{C}$ (Fig. 6b). As in the case of the one-step variant, this indicates that the martensitic transformation has begun after reaching the $\mathrm{M}_{\mathrm{s}}$ temperature. This demonstrates that the sample showed a higher $\mathrm{M}_{\mathrm{s}}$ temperature compared to the designed one $\left(400{ }^{\circ} \mathrm{C}\right)$. This is due to the propensity of high-Mn forged steels to develop segregation bands [35], which alter phase transformation temperatures and kinetics. In this sense, and due to their small size, dilatometric samples are very susceptible to show very diferent dilatometric behaviours for the same heat treatment [41]. See for example Fig. 6a, where the behaviour during heating to the austenitisation temperatures in both samples do not overlap.

The graph in Fig. 6c shows the first step of isothermal holding $\left(400{ }^{\circ} \mathrm{C}\right)$. As in the case of one-step sample treated at $350{ }^{\circ} \mathrm{C}$, after a partial martensitic transformation in the $400{ }^{\circ} \mathrm{C}-120 \mathrm{~s} / 350{ }^{\circ} \mathrm{C}-780 \mathrm{~s}$ sample there is much more intense start of bainitic transformation compared to the $400{ }^{\circ} \mathrm{C}-240 \mathrm{~s} / 350{ }^{\circ} \mathrm{C}-660 \mathrm{~s}$ sample. The martensite formed during cooling limited the extent of the bainitic transformation (RCL lower by approx. $0.1 \%$ compared to a $350{ }^{\circ} \mathrm{C}-900 \mathrm{~s}$ sample after the same time-120 s). In both cases, the curve indicates that the bainitic transformation is not completed, especially for the first step time equal to $120 \mathrm{~s}$. The RCL during cooling between isothermal steps (Fig. 6d) shows the absence of phase transformations, which indicates a decrease in the $\mathrm{M}_{\mathrm{s} \gamma}$. The second step of isothermal holding (Fig. 6e) occurring at $350{ }^{\circ} \mathrm{C}$ indicates that in both cases, there is further bainitic transformation. Its intensity was much lower as evidenced by about ten times lower RCL compared to the first step. This means that a lower amount of bainite was formed during this step presumably due to the remaining, small amount of austenite capable for the transformation. However, it can be seen that the $400{ }^{\circ} \mathrm{C}-120 \mathrm{~s} / 350{ }^{\circ} \mathrm{C}-780 \mathrm{~s}$ sample has a RCL two times higher than that of the $400{ }^{\circ} \mathrm{C}-240 \mathrm{~s} / 350{ }^{\circ} \mathrm{C}-660 \mathrm{~s}$ sample after approx. $600 \mathrm{~s}$, which is consistent with the fact that more austenite is available for transformation in the second isothermal treatment in the former than in the latter case. Also in this case, the curves show that the transformation is not completed, as neither of both curves in Fig. 6e seem to reach a steady state. The graph showing the cooling stage (Fig. 6f) has not registered the start of the martensitic transformation. This means that the austenite remaining after the bainitic transformation has been stabilized.

The micrographs of two-step processed samples are shown in Fig. 7. The microstructure of the sample held 

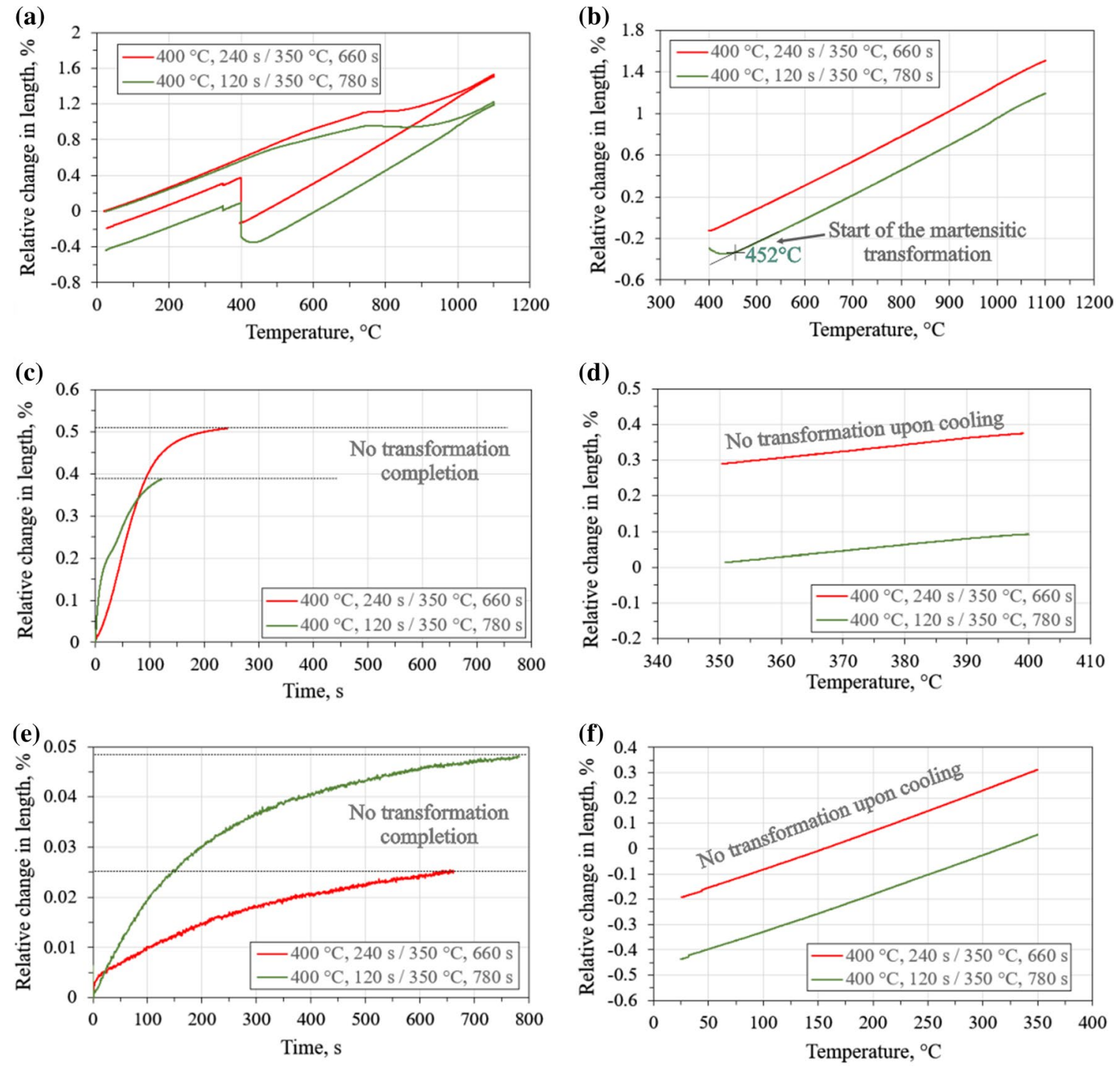

Fig. 6 Dilatometric curves of steel registered during double-step heat treatment: a heating and cooling throughout the entire heat treatment cycle; b cooling to isothermal holding temperature; $\mathbf{c} 1$ st isothermal

step; $\mathbf{d}$ cooling to the 2 nd step; e 2nd isothermal step; $\mathbf{f}$ cooling to room temperature

within 240 s during the first step at $400{ }^{\circ} \mathrm{C}$ comprises bainitic laths with embedded retained austenite (Fig. 7a, b), and its appearance is very similar to that obtained in one-step treatment performed at $400{ }^{\circ} \mathrm{C}$, Fig. 5a, b, supporting the dilatometric observation that the bainitic transformation was almost finished during the first holding (Fig. 6c). The more heterogenous microstructure revealed in the sample held $120 \mathrm{~s}$ during the first step, which shows numerous coalesced thick bainite plates, formed during the second step at $350{ }^{\circ} \mathrm{C}$, embedded among the fine plates formed at $400{ }^{\circ} \mathrm{C}$ (Fig. 7c). The higher magnification micrograph (Fig. 7d) reveals the complex microstructure of the $400{ }^{\circ} \mathrm{C}-120 \mathrm{~s} / 350{ }^{\circ} \mathrm{C}-780 \mathrm{~s}$ sample. Some of the bainitic plates are plate-like, whereas some others have a more granular shape. This is an indicative of the different conditions for bainitic transformation

due to the mentioned segregation. In addition to the typical bainitic plates and coalesced bainite some small fraction of very fine bainitic plates $\left(\alpha_{\mathrm{b}}\right)$ can be also visible in Fig. 7d. This fraction is presumably formed at a final stage of the second holding at $350{ }^{\circ} \mathrm{C}$ without enough time to be merged to the coalesced bainite.

\subsection{Hardness}

The average hardness value for a sample treated at one-step $400{ }^{\circ} \mathrm{C}$ was $367 \pm 1 \mathrm{HV}$, whereas for the sample heat-treated at $350{ }^{\circ} \mathrm{C}$, it was $372 \pm 3 \mathrm{HV}$ (Fig. 8). The small increase in hardness of the material processed at the lower temperature is caused by the combination of both, a finer bainitic ferrite and the presence of some fraction of tempered martensite 
Fig. 7 Microstructures of steel after double-step isothermal heat treatment: a $400{ }^{\circ} \mathrm{C}-240 \mathrm{~s} / 350{ }^{\circ} \mathrm{C}-660 \mathrm{~s}$ (LM); b

$400{ }^{\circ} \mathrm{C}-240 \mathrm{~s} / 350{ }^{\circ} \mathrm{C}-660 \mathrm{~s}$ (SEM); c

$400{ }^{\circ} \mathrm{C}-120 \mathrm{~s} / 350{ }^{\circ} \mathrm{C}-780 \mathrm{~s}$

(LM), d

$400{ }^{\circ} \mathrm{C}-120 \mathrm{~s} / 350{ }^{\circ} \mathrm{C}-780 \mathrm{~s}$

(SEM); $\gamma_{r}$ retained austenite, $\alpha_{b}$ bainite, $\alpha_{b}$, refined bainite, $\alpha_{c b}$ coalesced bainite
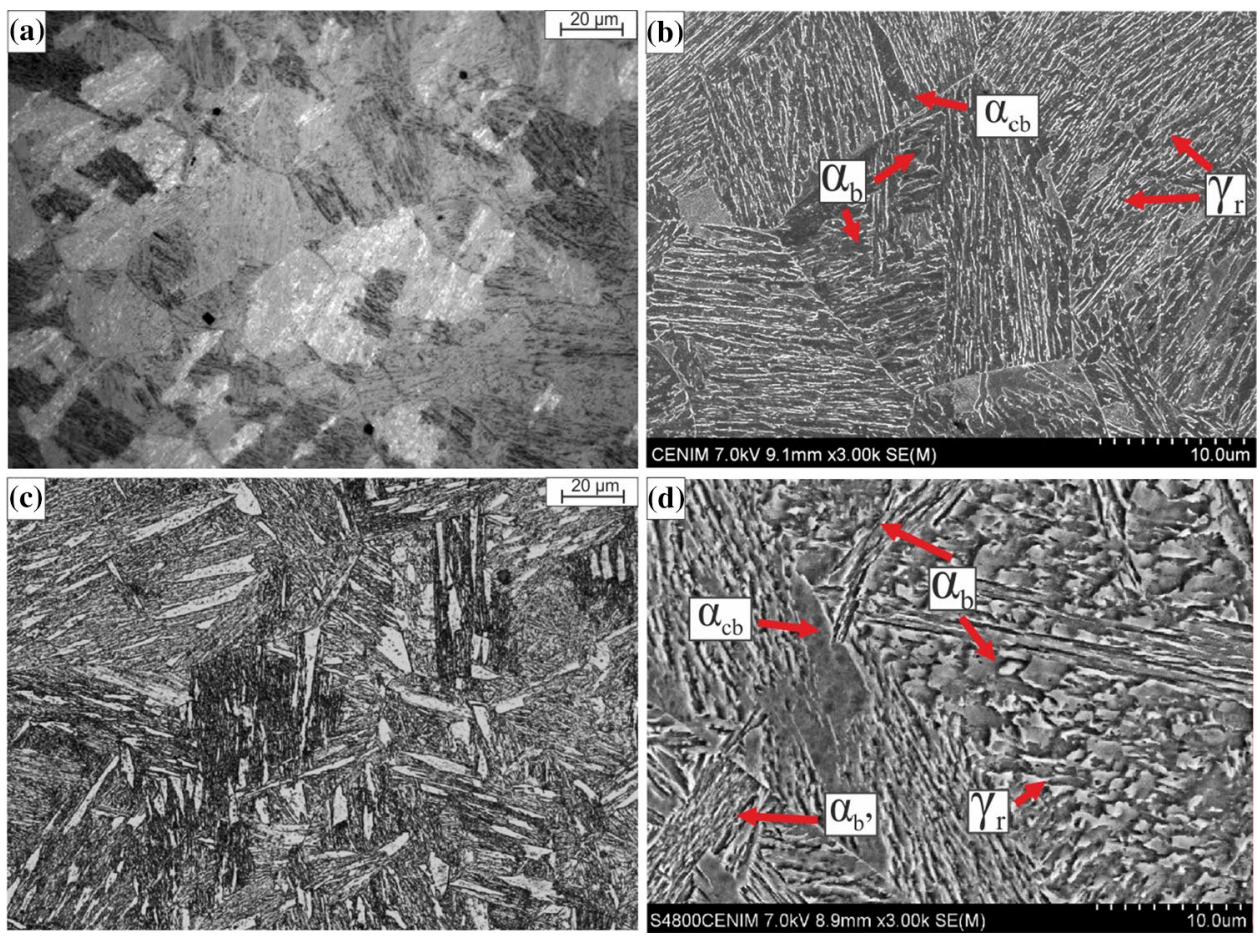

in the microstructure. The hardness relationship is identical for heat treated samples in a two-stage process. The $400{ }^{\circ} \mathrm{C}-240 \mathrm{~s} / 350{ }^{\circ} \mathrm{C}-660 \mathrm{~s}$ sample shows a hardness similar to the $400{ }^{\circ} \mathrm{C}-900 \mathrm{~s}$ sample. It is caused by the transformation of a significant part of bainite in the first stage of isothermal treatment, causing a weak effect of bainite obtained in the second stage on the increase of hardness. In the case of the $400{ }^{\circ} \mathrm{C}-120 \mathrm{~s} / 350{ }^{\circ} \mathrm{C}-780 \mathrm{~s}$ sample, the situation is similar, but the initial martensitic transformation results in a hardness similar to the $350{ }^{\circ} \mathrm{C}-900 \mathrm{~s}$ sample.

\section{Discussion}

The idea of austenite stabilization during the applied heat treatment (isothermal bainitic transformation) was its effective enrichment in carbon. This is possible due to the structural nature of bainite. This phase contains bainitic ferrite plates with a small carbon content, whereas the excess carbon forms carbides in the conventional upper or lower bainite. The use of the additions of $\mathrm{Al}$ and $\mathrm{Si}$ [42] affects the inhibition of the carbide formation. Thanks to this, the excess carbon during the isothermal holding step can be distributed into the remaining austenite lowering its $\mathrm{M}_{\mathrm{s \gamma}}$ temperature [43].

The results confirmed the propensity of the medium-Mn steel to the segregation of alloying elements described by Grajcar et al. [44] leading to some variations in the $M_{s}$ temperature. This is visible in Fig. 9, which presents the LM microstructure of the one-step $350{ }^{\circ} \mathrm{C}-900 \mathrm{~s}$ sample after the

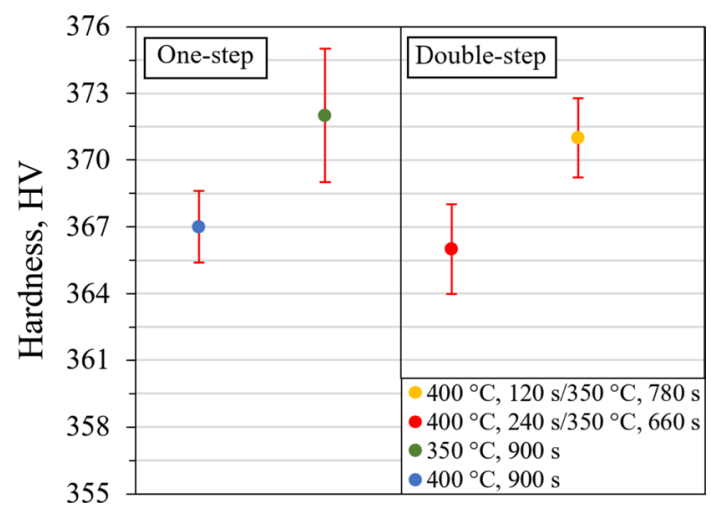

Fig. 8 Hardness results for one-step and double-step heat treatments

heat treatment. There are bands in the direction indicated by the arrow. According to Grajcar et al. [35], the difference of chemical composition ( $\mathrm{Mn}$ and $\mathrm{Al}$ ) in steel can lead to the variation of the $M_{s}$ temperature of steel in the range from 378 to $434{ }^{\circ} \mathrm{C}$. This explains why in case of the double-step heat treatment the martensitic transformation is present during the cooling step to $400{ }^{\circ} \mathrm{C}$ (Fig. 4b). According to the calculations performed for the $\mathrm{Al}$ and $\mathrm{Mn}$ contents in steel corresponding to the highest $\mathrm{M}_{\mathrm{s}}$ temperature (Fig. 10), the formation of martensite is possible and the amount of it is approx. $7 \%$.

For the one-step heat treatment at $350{ }^{\circ} \mathrm{C}$, the JMatPro calculations (Fig. 11) show that the amount of martensite formed during cooling to $350{ }^{\circ} \mathrm{C}$ is approx. $35 \%$. The formation of the martensite accelerates the bainite formation 


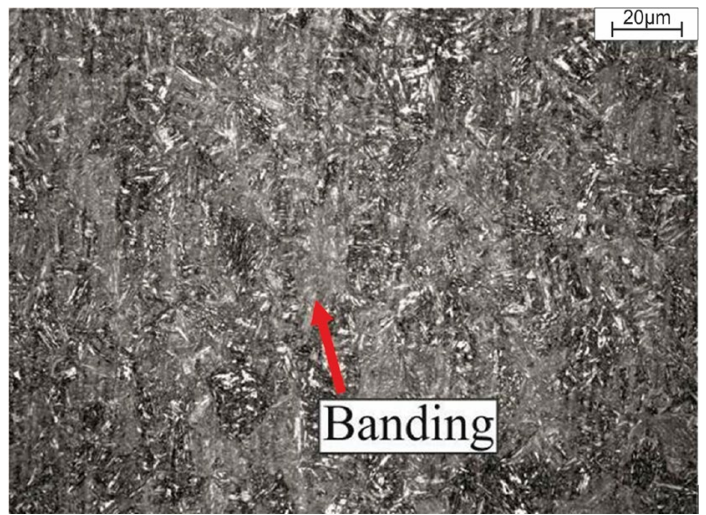

Fig. 9 Microsegregation bands in the microstructure of the steel after heat treatment at $350{ }^{\circ} \mathrm{C}$ for $900 \mathrm{~s}$

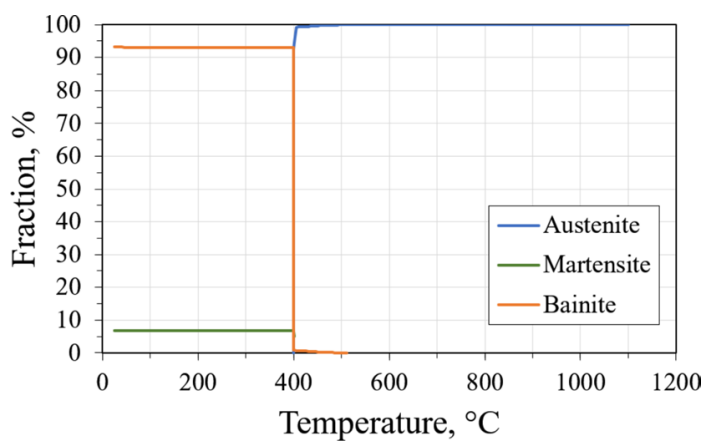

Fig. 10 Calculations of the phase transformation using the JMatPro simulating the composition with the highest $\mathrm{Al}$ and lowest $\mathrm{Mn}$ contents

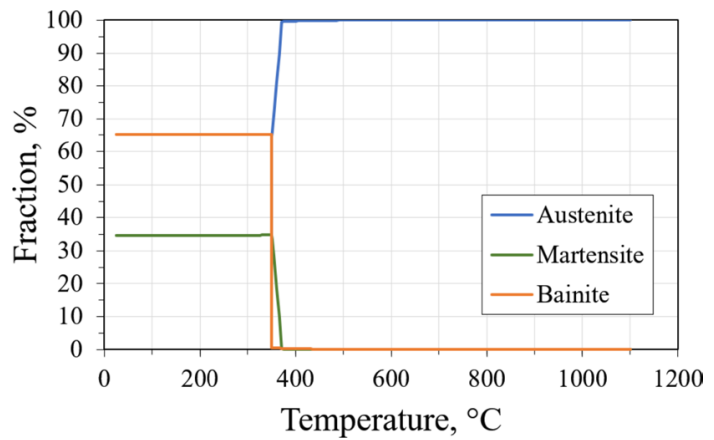

Fig. 11 Calculations of the phase transformation using the JMatPro simulating the one-step heat treatment at $350{ }^{\circ} \mathrm{C}$

during the isothermal holding as presented in Figs. $4 \mathrm{c}$ and 6c.

In both cases, crossing $\mathrm{M}_{\mathrm{s}}$ temperature during cooling led to similar results like in previous studies $[45,46]$ regarding the impact of prior martensite on the kinetics of bainitic transformation. This is due to the increase in the number of nucleation sites and the intensification of the bainite nucleation rate through the formed martensitic laths. It also affects the shortening of the incubation and completion times of bainitic transformation. In double-step heat treatment, the application of the first step of isothermal holding allowed for the partial stabilization of austenite, and thus a decrease in the temperature of bainitic transformation without entering the martensitic region. This made it possible to perform the treatment at a temperature lower than the initial $\mathrm{M}_{\mathrm{s}}$ of steel, which was the main aim of the study. The results have also shown that along with the decrease in the isothermal temperature from $400{ }^{\circ} \mathrm{C}$ to $350{ }^{\circ} \mathrm{C}$, the bainitic transformation is characterized by the lower dynamics generating less signal of the processed sample.

Thermodynamic calculations determined the duration of bainitic transformation at $400{ }^{\circ} \mathrm{C}$ for $300 \mathrm{~s}$. The dilatometric curve of the $400{ }^{\circ} \mathrm{C}-900 \mathrm{~s}$ sample reaches a plateau after approx. $340 \mathrm{~s}$ (Fig. 6c), which indicates the end of this transformation. At the same time, the relative change in length of the sample at the end of the bainitic transformation is about $0.55 \%$. In the case of the $400{ }^{\circ} \mathrm{C}-240 \mathrm{~s} / 350{ }^{\circ} \mathrm{C}-660 \mathrm{~s} \mathrm{sam}$ ple, it reached a relative change in length of approx. $0.5 \%$ at the end of the first isothermal step (Fig. 6c). This shows that the bainitic transformation has almost been completed, which limits the possibility of bainitic transformation in the second stage.

The dilatometric curve for the $400{ }^{\circ} \mathrm{C}-120 \mathrm{~s} / 350{ }^{\circ} \mathrm{C}-780 \mathrm{~s}$ sample is disturbed by earlier martensitic transformation. This makes it impossible to directly compare both curves. However, smaller RCL (0.45\%) indicates that the bainitic transformation at this step occurred to a less extent, allowing more transformation in the second step. Note that in that step, the RCL (Fig. 6e) is almost three times higher in the $400{ }^{\circ} \mathrm{C}-120 \mathrm{~s} / 350{ }^{\circ} \mathrm{C}-780 \mathrm{~s}$ sample when compared to the $400{ }^{\circ} \mathrm{C}-240 \mathrm{~s} / 350^{\circ} \mathrm{C}-660$ s sample.

In both cases, during cooling to the second step (Fig. 6d), there was no martensitic transformation, which indicates a partial stabilization of austenite. To sum up, apart from the earlier martensitic transformation, the shorter time of the first isothermal step (sufficient for austenite stabilization) influenced the increase in the intensity of bainitic transformation in the second step. This is caused by the retention of a larger austenite fraction to the second step of the treatment. The small amount of bainite obtained in the second stage means that it would be beneficial to further shorten the first isothermal stage.

The analysis of microscopic images of samples indicates that the decrease in isothermal holding temperature resulted in a decrease in the overall size of bainitic structures. However, at $350{ }^{\circ} \mathrm{C}$, thick coalesced bainite is also identified, which is in agreement with observations in [47]. Coalesced bainite is believed to be the result of the joining of bainitic plates with the same crystallographic orientation [48]. This is possible due to an increased driving force 
of bainitic transformation at this temperature and the slow partitioning of carbon from supersaturated ferrite to austenite. Thin austenite films, previously separating bainitic plates, are eliminated in the coalescence process, which is only possible when a very high driving force and low transformation temperatures are available [49]. Research to date indicates the susceptibility of high-strength steels with $\mathrm{Mn}$ above 2\% to form coalesced bainite [47].

\section{Conclusions}

The work concerned a detailed study of the physical simulation and dilatometric study of double-step heat treatment of the 3.3 wt. \% Mn, 0.17 wt.\% C, 1.6 wt.\% Al, 0.23 wt.\% Mo and 0.22 wt.\% Si medium-Mn steel. Calculations of equilibrium and non-equilibrium cooling and simulations of the developed thermal cycles were performed. The physical simulations of the one-step and novel two-step heat treatments were performed in the dilatometer. Microstructural characterization was performed to be linked with the dilatometric analysis. The main findings of the present study are as follows:

- Both one-step and two-step heat treatments at $400{ }^{\circ} \mathrm{C}$, $350{ }^{\circ} \mathrm{C}$ and $400 / 350{ }^{\circ} \mathrm{C}$ allowed to obtain a bainitic structure with a high fraction of residual austenite;

- Lowering the temperature of one-step isothermal holding allows the bainite refinement and thus adjacent retained austenite;

- The increased Mn content in steel increases its susceptibility to form coalesced bainite resulting in the partial formation of thicker plates despite a decrease in a process temperature from 400 to $350{ }^{\circ} \mathrm{C}$;

- The initiation of martensitic transformation significantly accelerates and increases the intensity of bainitic transformation;

- The higher fraction of low-temperature bainite produced during the second step of the treatment at $350{ }^{\circ} \mathrm{C}$ was produced for the earlier holding at $400{ }^{\circ} \mathrm{C}$ within $120 \mathrm{~s}$. This was due to the high rate of bainitic transformation at $400{ }^{\circ} \mathrm{C}$. The holding within $240 \mathrm{~s}$ at $400{ }^{\circ} \mathrm{C}$ during the first step of the double-step treatment produces microstructures very similar to those obtained during one-step treatment at $400{ }^{\circ} \mathrm{C}$ due to the fast kinetics of bainitic transformation.

- The samples produced in all variants of the heat treatments show the similar hardness at a level of $370 \mathrm{HV}$.
Funding The financial support of the National Science Center, Poland, is gratefully acknowledged, Grant no. 2017/27/B/ST8/02864.

\section{Compliance with ethical standards}

Conflict of interest The authors declare no conflict of interest.

Ethical statement The authors state that the research was conducted according to ethical standards.

Open Access This article is licensed under a Creative Commons Attribution 4.0 International License, which permits use, sharing, adaptation, distribution and reproduction in any medium or format, as long as you give appropriate credit to the original author(s) and the source, provide a link to the Creative Commons licence, and indicate if changes were made. The images or other third party material in this article are included in the article's Creative Commons licence, unless indicated otherwise in a credit line to the material. If material is not included in the article's Creative Commons licence and your intended use is not permitted by statutory regulation or exceeds the permitted use, you will need to obtain permission directly from the copyright holder. To view a copy of this licence, visit http://creativecommons.org/licenses/by/4.0/.

\section{References}

1. Speer J, Rana R, Matlock D, Glover A, Thomas G, De Moor E. Processing variants in medium-Mn steels. Metals. 2019;9:771.

2. Lee Y-K, Han J. Current opinion in medium manganese steel. J Mater Sci Technol. 2015;31:843-56.

3. Morawiec M, Grajcar A, Zalecki W, Garcia-Mateo C, Opiela M. Dilatometric study of phase transformations in $5 \mathrm{Mn}$ steel subjected to different heat treatments. Materials. 2020;13:958.

4. Soleimani M, Kalhor A, Mirzadeh H. Transformation-induced plasticity (TRIP) in advanced steels: a review. Mater Sci Eng A. 2020;795:140023

5. Chiang J, Lawrence B, Boyd JD, Pilkey AK. Effect of microstructure on retained austenite stability and work hardening of TRIP steels. Mater Sci Eng A. 2011;528:4516-21.

6. Schneider R, Steineder K, Krizan D, Sommitsch C. Effect of the heat treatment on the microstructure and mechanical properties of medium-Mn-steels. J Mater Sci Technol. 2019;35:2045-53.

7. $\mathrm{Hu} \mathrm{B}$, Luo H. Microstructures and mechanical properties of $7 \mathrm{Mn}$ steel manufactured by different rolling processes. Metals. 2017;7:464

8. Grajcar A, Skrzypczyk P, Woźniak D. Thermomechanically rolled medium-Mn steels containing retained austenite. Arch Metall Mater. 2014;59:1691-7.

9. Lee S-J, Lee S, De Cooman BC. Mn partitioning during the intercritical annealing of ultrafine-grained $6 \% \mathrm{Mn}$ transformationinduced plasticity steel. Scr Mater. 2011;64:649-52.

10. De Moor E, Matlock DK, Speer JG, Merwin MJ. Austenite stabilization through manganese enrichment. Scr Mater. 2011;64:185-8.

11. Gibbs PJ, De Moor E, Merwin MJ, Clausen B, Speer JG, Matlock DK. Austenite stability effects on tensile behavior of manganeseenriched-austenite transformation-induced plasticity steel. Metall Mater Trans A. 2011:42:3691-702.

12. Grajcar A, Zalecki W, Burian W, Kozłowska A. Phase equilibrium and austenite decomposition in advanced high-strength mediumMn bainitic steels. Metals. 2016:6:248 
13. Grajcar A, Kwaśny W, Zalecki W. Microstructure-property relationships in TRIP aided medium-C bainitic steel with lamellar retained austenite. Mater Sci Technol. 2015;31:781-94.

14. Caballero FG, Bhadeshia HKDH, Mawella KJA, Jones DG, Brown P. Very strong low temperature bainite. J Mater Sci Technol. 2002;18:279-84.

15. Garcia-Mateo C, Caballero FG, Bhadeshia HKDH. Low temperature bainite. J Phys IV France. 2003;112:285-8.

16. Yoozbashi MN, Yazdani S, Wang TS. Design of a new nanostructured, high-Si bainitic steel with lower cost production. Mater Des. 2011;32:3248-53.

17. Caballero FG, GarcíA-Mateo C, Chao J, Santofimia MJ, Capdevila C, de Andrés CG. Effects of morphology and stability of retained austenite on the ductility of TRIP-aided bainitic steels. ISIJ Int. 2008;48:1256-62.

18. Garcia-Mateo C, Caballero FG, Chao J, Capdevila C, de Andres CG. Mechanical stability of retained austenite during plastic deformation of super high strength carbide free bainitic steels. J Mater Sci. 2009;44:4617-24.

19. Singh SB, Bhadeshia HKDH. Estimation of bainite plate-thickness in low-alloy steels. Mater Sci Eng A. 1998;245:72-9.

20. García-Mateo C, Caballero FG, Bhadeshia HKDH. Mechanical properties of low-temperature bainite. Mater Sci Forum. 2005;500-501:495-502.

21. Bhadeshia HKDH. Bulk nanocrystalline steel. Ironmak Steelmak. 2005;32:405-10.

22. Shen YF, Qiu LN, Sun X, Zuo L, Liaw PK, Raabe D. Effects of retained austenite volume fraction, morphology, and carbon content on strength and ductility of nanostructured TRIP-assisted steels. Mater Sci Eng A. 2015;636:551-64.

23. Shen YF, Liu YD, Sun X, Wang YD, Zuo L, Misra RDK. Improved ductility of a transformation-induced-plasticity steel by nanoscale austenite lamellae. Mater Sci Eng A. 2013;583:1-10.

24. Long XY, Zhang FC, Kang J, Lv B, Shi XB. Low-temperature bainite in low-carbon steel. Mater Sci Eng A. 2014;594:344-51.

25. Long XY, Kang J, Lv B, Zhang FC. Carbide-free bainite in medium carbon steel. Mater Des. 2014;64:237-45.

26. Avishan B, Tavakolian M, Yazdani S. Two-step austempering of high performance steel with nanoscale microstructure. Mater Sci Eng A. 2017;693:178-85.

27. Soliman M, Mostafa H, El-Sabbagh AS, Palkowski H. Low temperature bainite in steel with $0.26 \mathrm{wt} \%$ C. Mater Sci Eng A. 2010;527:7706-13.

28. Wang XL, Wu KM, Hu F, Yu L, Wan XL. Multi-step isothermal bainitic transformation in medium-carbon steel. Scr Mater. 2014;74:56-9.

29. Mousalou H, Yazdani S, Avishan B, Ahmadi NP, Chabok A, Pei Y. Microstructural and mechanical properties of low-carbon ultrafine bainitic steel produced by multi-step austempering process. Mater Sci Eng A. 2018;734:329-37.

30. Duong VT, Song YY, Park K-S, Bhadeshia HKDH, Suh D-W. Austenite in transformation-induced plasticity steel subjected to multiple isothermal heat treatments. Metall Mater Trans A. 2014;45:4201-9.

31. Sugimoto K, Sakaguchi J, Iida T, Kashima T. Stretch-flangeability of a high-strength TRIP type bainitic sheet steel. ISIJ Int. 2000;40:920-6.

32. Kim K-W, Il Kim K, Lee C-H, Kang J-Y, Lee T-H, Cho K-M, et al. Control of retained austenite morphology through double bainitic transformation. Mater Sci Eng A. 2016;673:557-61.
33. Mukherjee M, Mohanty ON, Hashimoto S, Hojo T, Sugimoto $\mathrm{K}$. Strain-induced transformation behaviour of retained austenite and tensile properties of TRIP-aided steels with different matrix microstructure. ISIJ Int. 2006;46:316-24.

34. Sugimoto K, Nakano K, Song S-M, Kashima T. Retained austenite characteristics and stretch-flangeability of high-strength low-alloy TRIP type bainitic sheet steels. ISIJ Int. 2002;42:450-5.

35. Grajcar A, Kalinowska-Ozgowicz E, Opiela M, Grzegorczyk B, Gołombek K. Effects of Mn and Nb on the macro- and microsegregation in high-Mn high-Al content TRIP steels. Arch Civ Mech Eng. 2011;49:10.

36. Sente Software Ltd. A collection of free downloadable papers on the development and application of JmatPro. 2005. https://www. sentesoftware.co.uk/biblio.html. Accessed 25 Mar 2020.

37. ASTM A1033-04. Standard practice for quantitative measurement and reporting of hypoeutectoid carbon and low-alloy steel phase transformations; ASTM International: West Conshohocken. 2004. https://www.astm.org/. Accessed 25 Mar 2020.

38. Navarro-López A, Sietsma J, Santofimia MJ. Effect of prior athermal martensite on the isothermal transformation kinetics below Ms in a low-C high-Si steel. Metall Mater Trans A. 2016;47:1028-39.

39. Guo H, Feng X, Zhao A, Li Q, Ma J. Influence of prior martensite on bainite transformation, microstructures, and mechanical properties in ultra-fine bainitic steel. Materials. 2019;12:527.

40. Caballero FG, Chao J, Cornide J, García-Mateo C, Santofimia MJ, Capdevila C. Toughness of advanced high strength bainitic steels. Mater Sci Forum. 2010;638-642:118-23.

41. Sourmail T, Smanio V. Determination of Ms temperature: Methods, meaning and influence of "slow start" phenomenon. Mater Sci Technol. 2013;29(7):883-8.

42. Kuziak R, Kawalla R, Waengler S. Advanced high strength steels for automotive industry. Arch Civ Mech Eng. 2008;8:103-17.

43. Han DT, Xu YB, Zou Y, Hu ZP, Chen SQ, Yu YM. Effect of $\mathrm{Al}$ on the microstructure and mechanical properties of hot-rolled medium-Mn steel. Mater Sci Forum. 2018;941:292-8.

44. Grajcar A, Kamińska M, Opiela M, Skrzypczyk P, Grzegorczyk B, Kalinowska-Ozgowicz E. Segregation of alloying elements in thermomechanically rolled medium-Mn multiphase steels. J Achiev Mater Manuf Eng. 2012;55:256-64.

45. Chu C, Qin Y, Li X, Yang Z, Zhang F, Guo C, et al. Effect of two-step austempering process on transformation kinetics of nanostructured bainitic steel. Materials. 2019;12:166.

46. Sarizam M, Komizo Y. Effects of holding temperature on bainite transformation in Cr-Mo steel. J Mech Eng Sci. 2014;7:1103-14.

47. Bhadeshia HKDH, Edmonds DV. The bainite transformation in a silicon steel. Metall Trans A. 1979;10:895-907.

48. Chang LC, Bhadeshia HKDH. Microstructure of lower bainite formed at large undercoolings below bainite start temperature. Mater Sci Technol. 1996;12:233-6.

49. Bhadeshia HKDH, Keehan E, Karlsson L, Andren HO. Coalesced Bainite. Trans Indian Inst Metals. 2006;59:689-94.

Publisher's Note Springer Nature remains neutral with regard to jurisdictional claims in published maps and institutional affiliations. 